\title{
Estrogen is an important mediator of mast cell activation in ovarian endometriomas
}

\author{
Tian-Hong Zhu, Shao-Jie Ding, Tian-Tian Li, Li-Bo Zhu, Xiu-Feng Huang and Xin-Mei Zhang \\ Women's Hospital, Zhejiang University School of Medicine, Hangzhou, People's Republic of China \\ Correspondence should be addressed to X-M Zhang; Email: zhangxinm@zju.edu.cn
}

\begin{abstract}
Endometriosis is an estrogen-dependent disease. Previous research has shown that abnormal enzymes associated with estrogen (E2) metabolism and an increased number of mast cells (MCs) in endometriomas are implicated in the pathogenesis of endometriosis. However, it remains unclear how MCs mediate the role of E2 in endometriosis. Accordingly, we investigated whether E2 was associated with the number of MCs, and the rate of degranulation, in local ovarian endometriomas, as well as the role of E2 on MCs during the pathogenesis of endometriosis. Using enzyme-linked immunosorbent assay and immunohistochemistry, we found that concentrations of E2, and the number and activity of MCs, were significantly higher in ovarian endometriomas than in controls, and that these parameters were correlated with the severity of endometriosis-associated dysmenorrhea. By measuring the release of hexosaminidase, we found that the rate of RBL2H3 cell degranulation increased after E2 treatment. Furthermore, activation of RBL2H3 cells by E2 was found to trigger the release of biologically active nerve growth factor, which promotes neurite outgrowth in PC12 cells and also sensitizes dorsal root ganglion cells via upregulation of Nav1.8 and transient receptor potential cation channel (subfamily V member 1 ) expression levels. When treated with E2, endometriotic cells could promote RBL2H3 cell recruitment by upregulating expression levels of stem cell factor, transforming growth factor- $\beta$ and monocyte chemoattractant protein-1; these observations were not evident with control endometrial cells. Thus, elevated E2 concentrations may be a key factor for degranulation and recruitment of MCs in ovarian endometriomas, which play a key role in endometriosis-associated dysmenorrhea.

Reproduction (2018) 155 73-83
\end{abstract}

\section{Introduction}

Endometriosis is characterized by the presence of functional endometrium outside of the uterine cavity, resulting in dysmenorrhea, dyspareunia, pelvic pain and infertility (Eskenazi \& Warner 1997). Endometriosis is considered as not only a chronic inflammatory disorder butalsoan estrogen-dependent disease(Burney \& Giudice 2012, Xiong et al. 2015). Although serum estrogen (E2) levels are similar when compared between women with endometriosis and those without (Huhtinen et al. 2012), E2 concentrations in endometriotic lesions are known to be elevated (Rizner 2009). These elevated concentrations of E2 are often attributed to the upregulated expression of aromatase (CYP19) and the downregulated expression of $17 \beta$-hydroxysteroid dehydrogenase (17BHSD) type 2 and sulfate transferase in endometriotic lesions (Zeitoun et al. 1998, Zeitoun \& Bulun 1999, Rizner 2009, Ferrero et al. 2014). Interestingly, the number of mast cells (MCs) and activated MCs is also increased in endometriotic lesions (Sugamata et al. 2005). Furthermore, stem cell factor (SCF), also known as MC growth factor, is also known to increase in the peritoneal fluid of women with endometriosis (Osuga et al. 2000). Basing on these findings, we hypothesized that E2 may be involved in the pathogenesis of endometriosis by mediating MCs.

MCs are key molecules in the immune system, particularly in terms of allergic reactions. In women with endometriosis, MCs in endometriotic lesions are located around blood vessels and also extremely close to nerve fibers. (Matsuzaki et al. 1998, Anaf et al. 2006). In our previous animal studies, the number of MCs and that of activated MCs in endometriotic lesions were associated with the levels of serum E2 and tumor necrosis factor- $\alpha$ (TNFA) and the expression of nerve growth factor (NGF) (Lin et al. 2015). Estrogen receptors are expressed on MCs (Zaitsu et al. 2007) and researches have shown that activated MCs release both TNFA and NGF (Church \& Levi-Schaffer 1997, Kleij \& Bienenstock 2005). These results suggest that MCs may mediate the role of E2 in the pathogenesis of endometriosis, although the direct effect of E2 upon TNFA and NGF cannot be excluded.

Recently, ultra-micronized palmitoylethanolamide (PEA, an endogenous fatty acid amide that has the capacity to stabilize MCs, thereby controlling inflammation associated with MC activation) was used to treat a rat endometriosis model (luvone et al. 2016). The results of this study showed that PEA-treated rats experienced less pain and had small endometriotic 
cysts, a low number of MCs and low levels of both NGF and vascular endothelial growth factor in their endometriotic lesions (luvone et al. 2016). Our previous animal studies also showed that the number of activated MCs, and the ratio of degranulation/total number of MCs in endometriotic lesions, as well as serum TNFA levels, considerably decreased when model rats were treated with sodium cromoglycate, an MC stabilizer that inhibits the release of histamine (Zhu et al. 2015). These findings further support the fact that E2 promotes the growth of endometriotic lesions and triggers pain by activating MCs, which subsequently release a variety of mediators. However, how E2 recruits and activates MCs to promote the growth of endometriotic lesions and thus trigger the pain associated with endometriosis requires further investigation.

In the present study, we aimed to investigate the effects of local E2 upon the recruitment and degranulation of MCs in endometriotic lesions and determine whether these cells are involved in the pain associated with endometriosis and the growth of endometriotic lesions. First, we determined the concentrations of $\mathrm{E} 2$, the number of activated MCs and the ratio of degranulation/total number of MCs in ovarian endometriotic lesions. We also determined the correlations between local E2 levels, the number of degranulated MCs and a variety of clinical parameters. Secondly, we investigated the effects of E2 on the degranulation of RBL-2H3 cells and then induced neurite outgrowth of PC12 cells, along with the peripheral sensitivity of dorsal root ganglion (DRG) cells, in response to high concentrations of E2, a condition similar to that seen in endometriosis. Finally, we observed the migration of $\mathrm{RBL} 2 \mathrm{H} 3$ cells using a trans-well migration assay and detected the release of MC-associated mediators in ovarian endometriotic cells in vitro.

\section{Materials and methods}

\section{Patients}

We recruited 80 women undergoing laparoscopic surgery for ovarian endometriosis, uterine leiomyoma and infertility in our hospital between January 2015 and October 2016. These patients were classified into two groups depending on surgical findings (Chapron et al. 2011): an endometriosis group $(n=41)$ consisting of subjects with histologically proven endometriosis and a control group $(n=39)$ consisting of subjects who did not show any macroscopic signs of endometriosis following meticulous exploration of the abdominal cavity during surgery. Endometriosis was graded according to the revised American Fertility Society (r-AFS) classification (Canis et al. 1997). Patient characteristics are shown in Table 1, which demonstrates clinical heterogeneity between different cases. The severity of pain was documented using a standardized questionnaire with a Visual Analog Scale (VAS), which was measured on a scale of $0-10$; a score of $1-3$ was considered mild, 4-6 as moderate and $>6$ as severe pain (Priya et al. 2016). The VAS score was self-assessed by each patient prior to treatment. All study subjects had a regular menstrual cycle, and none had received hormonal therapy for at least three months before surgery. In addition, we excluded all patients who suffered from other apparent systemic or local pain conditions, except for endometriosis-related dysmenorrhea, and those diagnosed with autoimmune diseases (Sinaii et al. 2002).

\section{Tissue collection}

Ectopic and eutopic endometrial samples were acquired from women with ovarian endometriomas who were undergoing hysteroscopy and laparoscopy. Samples of normal endometrium were collected from patients undergoing hysterectomy with uterine leiomyoma or hysteroscopy with infertility. We routinely collected endometrial samples during or immediately after the surgical procedure. Specimens from women with or without endometriosis were fixed immediately in $10 \%$ neutral-buffered formalin for $24 \mathrm{~h}$ before processing and embedding in paraffin for immunohistochemistry in accordance with a standard protocol. Of these, specimens from 17 women with endometriosis and 18 women without endometriosis were immersed in liquid nitrogen and stored at $-80^{\circ} \mathrm{C}$ for enzyme-linked immunosorbent assay (ELISA). A number of specimens were also placed in Dulbecco's Modified Eagle Medium/F-12 (Sigma) at $4{ }^{\circ} \mathrm{C}$ for endometrial cell culture. Endometrial histology was dated according to the general classifications described before (Kelm Junior et al. 2008). Each patient provided informed consent to participate in the study, which was approved by the Human Ethics Committee of the Women's Hospital, School of Medicine, Zhejiang University.

\section{Isolation and culture of human ectopic and normal endometrial cells}

Endometriotic cyst walls and normal endometria in proliferative and secretory phases were collected from women with or without endometriomas at the time of laparoscopy and hysteroscopy. The phase of the menstrual cycle was determined by menstrual history and confirmed histologically. Samples were collected, washed with $1 \times$ phosphate-buffered saline (PBS) and transferred to the laboratory on ice. Fresh samples were dissected into small pieces and digested with type I collagenase (Life Technologies) for 60-90 min. Debris was removed by $100 \mu \mathrm{m}$ apertures sieves. Endometrial cells were then resuspended in DMEM/F12 medium containing $10 \%$ (V/V) fetal bovine serum and cultured at $37^{\circ} \mathrm{C}$ in a humidified $5 \% \mathrm{CO}_{2}$ in air $(\mathrm{V} / \mathrm{V})$.

\section{Cell lines}

A rat basophilic leukemia (RBL2H3) cell line, a mucosal mast cell analog (Barsumian et al. 1981), was purchased from American Type Culture Collection (ATCC) and grown in minimum Eagle's medium (Sigma) supplemented with 10\% heat-inactivated fetal calf serum (Gibco), $100 \mathrm{U} / \mathrm{mL}$ penicillin and $100 \mu \mathrm{g} / \mathrm{mL}$ streptomycin. PC12 cell line was selected as a neuronal model and purchased from the Chinese Academy of Sciences (Shanghai, China); this model has originally described by Greene and Tischler (Greene \& Tischler 1976). 
Table 1 Characteristics of recruited patients.

\begin{tabular}{|c|c|c|c|}
\hline Patient characteristics & $\begin{array}{c}\text { Endometriosis } \\
\quad(n=41)\end{array}$ & $\begin{array}{c}\text { Controls } \\
(n=39)\end{array}$ & $\boldsymbol{P}$ \\
\hline Age (years; mean \pm S.D.) & $35.2 \pm 6.7$ & $34.7 \pm 5.7$ & $0.694^{t}$ \\
\hline $\begin{array}{l}\text { Serum E2 level (median } \\
(\mathrm{IQR}))\end{array}$ & $371.5(541.0)$ & $250.5(246.9)$ & $0.536^{\mathrm{U}}$ \\
\hline \multicolumn{4}{|l|}{ Menstrual cycle $(n(\%))$} \\
\hline Proliferative phase & $31(75.6 \%)$ & $31(79.5 \%)$ & \\
\hline Secretory phase & $10(24.4 \%)$ & $8(20.5 \%)$ & \\
\hline \multicolumn{4}{|l|}{ rAFS stage $(n(\%))$} \\
\hline I & 0 & NA & \\
\hline II & 0 & NA & \\
\hline III & $15(36.6 \%)$ & NA & \\
\hline IV & $26(63.4 \%)$ & NA & \\
\hline \multicolumn{4}{|l|}{$\begin{array}{l}\text { Severity of dysmenorrhea } \\
\qquad(n(\%))\end{array}$} \\
\hline None & $11(26.8 \%)$ & $34(87.2 \%)$ & \\
\hline Mild & $8(19.5 \%)$ & $4(10.3 \%)$ & \\
\hline Moderate & $9(22.0 \%)$ & $1(2.6 \%)$ & \\
\hline Severe & $13(31.7 \%)$ & 0 & \\
\hline $\begin{array}{l}\text { Cyst diameter size }(\mathrm{cm} ; \\
\text { mean } \pm \text { s.D. })\end{array}$ & $5.2 \pm 1.7$ & NA & \\
\hline \multicolumn{4}{|c|}{$\begin{array}{l}\text { Co-occurrence of peritoneal } \\
\text { endometriosis }(n(\%))\end{array}$} \\
\hline No & $9(22.0 \%)$ & NA & \\
\hline Yes & $32(78.0 \%)$ & NA & \\
\hline \multicolumn{4}{|l|}{$\begin{array}{l}\text { Co-occurrence of deep } \\
\text { infiltrating } \\
\text { endometriosis }(n(\%))\end{array}$} \\
\hline No & 38 (92.7\%) & NA & \\
\hline Yes & $3(7.3 \%)$ & NA & \\
\hline
\end{tabular}

$\overline{\mathrm{IQR} \text {, interquartile range; rAFS, revised American Fertility Society; S.D., }}$ standard deviation; 'Student's $t$-test; ${ }^{\cup}$ Mann-Whitney $U$ test.

PC12 cells were cultured in a complete medium consisting of 85\% F-12 medium (Sigma), 10\% heat-inactivated horse serum (Gibco) and 5\% fetal calf serum (Gibco). In addition, we purchased a rat DRG cell line from the European Collection of Cell Cultures (Public Health England, UK). This was cultured in DMEM/F12 medium (Sigma), supplemented with 20\% fetal bovine serum (Gibco), $100 \mu \mathrm{g} / \mathrm{mL}$ streptomycin and $100 \mathrm{U} / \mathrm{mL}$ penicillin. All these three cell lines were maintained at $37^{\circ} \mathrm{C}$ in a humidified incubator with a $5 \% \mathrm{CO}_{2}$ atmosphere (V/V).

\section{Determination of endometrial E2 concentration}

The concentration of E2 in endometrial tissues was determined by an ELISA kit, which was used in accordance with the manufacturer's instructions (CSB-E05108h, CUSABIO, China). In brief, $100 \mathrm{mg}$ of endometrial tissue was rinsed with $1 \times \mathrm{PBS}$, homogenized in $1 \mathrm{~mL}$ of $1 \times \mathrm{PBS}$ and stored overnight at $-20^{\circ} \mathrm{C}$. Then, two freeze-thaw cycles were performed to break the cell membranes and the resulting homogenates were centrifuged at $5000 \mathrm{~g}, 2-8^{\circ} \mathrm{C}$, for $5 \mathrm{~min}$. The resultant supernatant was then removed and assayed immediately in accordance with the manufacturer's instructions. After $10 \mathrm{~min}$, the optical density for each well was determined with a microplate reader set to $450 \mathrm{~nm}$.

\section{Immunohistochemical staining}

Tissue blocks were prepared and sectioned at $4 \mu \mathrm{m}$ using routine deparaffinization and rehydration procedures. Sections were incubated with anti-mouse tryptase primary antibody (dilution 1:800, ab2378, Abcam) and anti-rabbit c-kit primary antibody (dilution 1:200, ab32363, Abcam) for $60 \mathrm{~min}$ at room temperature. After washing with $1 \times$ PBS, the sections were incubated with Envision-labeled polymer-alkaline phosphatase mouse/rabbit (Envision/HRP/Mo, GK400105; Envision/HRP/ Rb, GK400305/15, Novocastra, Newcastle upon Tyne, UK) for $60 \mathrm{~min}$. The antigen-antibody reaction was then visualized using diaminobenzidine as a chromogen (GK346810, Novocastra). After washing, the sections were counterstained with Mayer's hematoxylin, dehydrated and mounted with a mounting medium. Tonsils were used as a positive control, and HeLa-cultured cells were used as a negative control.

\section{Quantitation of degranulated MCs}

Degranulated MCs were counted under a light microscope as previously described (Sugamata et al. 2005). In brief, the degranulated MCs possessed an irregular shape with an uneven color and a non-complete cell membrane surface, while the granulated MCs were round or oval with uniform color and an intact cell membrane surface. In each sample, the number of cells per field ( $\times 20$ objective, $\times 10$ ocular) were counted in a total of five fields. Results were then expressed as a mean and standard error of the mean (S.E.M.). All slides were counted by two blinded observers.

\section{$R N A$ extraction and quantitative real-time polymerase chain reaction ( $R T-q P C R)$}

The specific steps for RNA isolation, cDNA synthesis and real-time RT-PCR were performed as previously described (Zenclussen et al. 2005). Real-time PCR was performed with an Applied Biosystems 7900HT system (Applied Biosystems) using SYBR Premix Ex TaqTM kit (Takara Bio). Specific primers used for amplification were synthesized by Generay (Shanghai, China) (Table 2). For each sample, an average cycle threshold (Ct) value was calculated from triplicate wells and the fold change was determined using the $2^{-\Delta \Delta \mathrm{Ct}}$ method.

\section{Measurement of RBL2H3 cell degranulation}

RBL2H3 cell degranulation was measured through the release of hexosaminidase (hex) (Dastych et al. 1999). First, RBL2H3 cells were distributed across 96-well flat bottom plates $\left(5 \times 10^{4}\right.$ cells/well), cultured for two days in estrogen-free medium, and then stimulated with different concentrations of E2 (E2759, Sigma) $\left(0,1,10,100,500,1000,10^{4}, 10^{5} \mathrm{pmol} / \mathrm{L}\right)$ at different times $(5,10,15,30,60,120 \mathrm{~min})$. Subsequently, degranulation was evaluated by the release of hex according to the protocol (Kuehn et al. 2010). Finally, plate absorbance was read at $405 \mathrm{nM}$ with a reference filter at $620 \mathrm{~nm}$, and the proportion of hex activity present in the supernatant was calculated as a percentage.

\section{Observation of neurite outgrowth of PC12 cells}

A bioassay using the PC12 cell line is commonly used to detect and measure biologically active NGF, which stimulates 
Table 2 List of primers used in this study.

\begin{tabular}{llll}
\hline Gene & Species & Forward primer & Reverse primer \\
\hline GAPDH & Human & GCCATCAATGACCCCTTCATT & TGACGGTGCCATGGAATTT \\
GAPDH & Rat & GGCACAGTCAAGGCTGAGAATG & ATGGTGGTGAAGACGCCAGTA \\
CYP19 & Human & TGGACACCTCTAACACGCTCTTC & GAGCTTGCCATGCATCAAAA \\
$17 B H S D 2$ & Human & AGGAATTGCGAAGAACCTGCT & CGGCCATGCATTGTTTGTAGT \\
SULT1E1 & Human & TGCAGAAAAGAAAACCTCATGAAT & ATGACCAGCCACCATTAGAAA \\
SCF & Human & AACCCAGGTGCTTTGAGAAG & CAATGCCACACACTGAGACA \\
TGFB & Human & TAGACCCTTTCTCCTCCAGGAGACG & GCTGGGGGTCTCCCGGCAAAAGGT \\
MCP1 & Human & AGGAAGATCTCAGTGCAGAGG & AGTCTTCGGAGTTTGGGTTTG \\
Nav1.8 & Rat & TGAGACCTGGGAGAAGTTCG & AGCAGCGACCT CATCTTCAT \\
Trpv 1 & Rat & GACATGCCACCCAGCAGG & TCAATTCCCACACACCTCCC \\
\hline
\end{tabular}

MCP1, monocyte chemoattractant protein-1; SULT1E1, sulfotransferase family 1E member 1; SCF, stem cell factor; TGFB, transforming growth factor- $\beta$; Trpv1, transient receptor potential cation channel subfamily $\vee$ member 1 .

neurite outgrowth of PC12 cells (Woo et al. 1995). To detect and quantify the biological activity of NGF in RBL2H3 cell supernatants after stimulation with E2, PC12 cells were re-plated onto 24-well culture plates at a concentration of $2 \times 10^{4}$ cells/well, and RBL2H3 cell culture supernatants $\left(1 \times 10^{6} \mathrm{cells} / \mathrm{mL}\right)$, or serial dilutions of NGF as controls, were added to the wells. After $24 \mathrm{~h}$, the number of PC12 cells showing neurite outgrowth was counted on a dark field inverted microscope (Nikon). Cells with at least two neurites, which were more than $50 \mu \mathrm{m}$ long, were judged as neurite outgrowth-positive cells. All samples were tested in duplicate, and quantification was performed in a blinded manner.

\section{Co-culture of RBL2H3 cells and DRG cells in vitro}

RBL2H3 cells were cultured in $0.4 \mu \mathrm{m}$ filter inserts (Corning 3412 ) in DMEM-F12+10\% FBS until $70-80 \%$ confluency. For experimentation, the RBL2H3 cell-bearing inserts were rinsed with DMEM-F12 and placed in wells so as to overlay each DRG cell-derived culture. The total amount of medium used was $4 \mathrm{~mL}$ per well for 6 -well plates $(1.5 \mathrm{~mL}$ per insert and $2.5 \mathrm{~mL}$ per well). For DRG monoculture, cells were cultured directly in wells with or without E2 stimulation (500 pmol/L). For the co-culture system, cultures were treated with either E2 or ICI182780 (S1191, Selleck, USA), as indicated. Then, $24 \mathrm{~h}$ after treatment, total RNA was extracted from DRG cells, and real-time RT-PCR was performed to detect whether MCs mediate the role of E2 in the peripheral sensitization of DRG cells.

\section{Chemotactic movement of RBL2H3 cells}

First, peritoneal fluid was collected from patients with or without endometriosis. Then, ovarian endometriotic cells and endometrial cells were cultured in vitro, and the cell supernatant was collected after $24 \mathrm{~h}$ culture with E2 stimulation. The migration of RBL2 $\mathrm{H} 3$ cells was evaluated using the trans-well migration assay ( $8 \mu \mathrm{m}$, Corning 3422$)$. In the upper chamber, RBL2H3 cells were evenly spread using serum-free medium (Opti-MEM, Gibco) and $500 \mu \mathrm{L}$ of either peritoneal fluid or cell supernatant was added to the lower chamber through the side wall. After incubation for different time periods, cells were stained with $0.1 \%$ crystal violet. Digital images were then acquired and five views per hole were quantified.

\section{Statistical analysis}

Statistical analysis was carried out using GraphPad Prism Software. All experiments were performed at least three times. For normally distributed data, we used the Student's $t$-test and one-way analysis of variance (ANOVA), followed by Scheffe's test, for group comparisons. Data that were not normally distributed were analyzed with the Mann-Whitney $U$ test. Analysis of real-time PCR data was performed using transformed values. Correlations were assessed by Pearson correlation and statistical significance was defined as when $P<0.05$.

\section{Results}

\section{High concentrations of E2 in ovarian endometriotic lesions are positively correlated with endometriosis- related dysmenorrhea}

No significant difference in age was observed between women with endometriosis and those without $(P=0.694)$. The concentrations of E2 were

Table 3 Concentration of E2 in endometrium $(\mathrm{pg} / \mathrm{mL})$.

\begin{tabular}{|c|c|c|c|c|}
\hline Group & Number & Mean \pm S.D. & Proliferative phase $(n)$ & Secretory phase $(n)$ \\
\hline Ec & 17 & $1560.7 \pm 90.2^{* * *}$ & $1624.5 \pm 274.5(n=9)^{* * *}$ & $1496.9 \pm 180.5(n=8)^{* * *}$ \\
\hline $\mathrm{Eu}$ & 17 & $1870.5 \pm 269.0 * * *$ & $2060.7 \pm 214.9(n=11)^{* * *}$ & $1680.3 \pm 195.0(n=6)^{* * * \#^{1}}$ \\
\hline $\mathrm{Nm}$ & 18 & $622.9 \pm 193.0$ & $759.4 \pm 175.6(n=13)$ & $486.4 \pm 148.7(n=5) \#^{2}$ \\
\hline
\end{tabular}

***Indicates $P<0.001$ for comparisons of E2 in each phase with normal endometrium while $\#^{1}$ indicates $P=0.003$ and $\#^{2}$ indicates $P=0.007$ for comparisons of E2 between the proliferative and secretory phase in one group.

Ec, ectopic endometrium; Eu, eutopic endometrium; Nm, normal endometrium. 

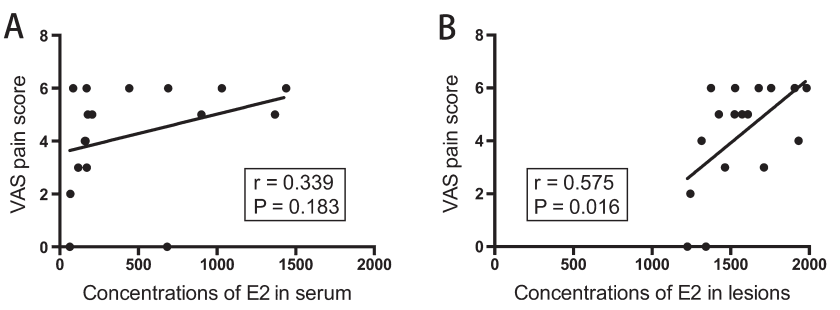

Figure 1 High concentrations of E2 in ovarian endometriotic lesions are positively correlated with endometriosis-related dysmenorrhea. (A) Correlation between concentrations of E2 in the serum and the degree of dysmenorrhea in patients with endometriosis. (B) Correlation between concentrations of E2 in endometriotic lesions and the degree of dysmenorrhea in patients with endometriosis. Each dot represents data from an individual patient. The Pearson coefficient of correlation and the significance of this correlation are shown in the lower right corner.

$1560.7 \pm 90.2 \mathrm{pg} / \mathrm{mL}$ in ectopic lesions $(n=17)$, $1870.5 \pm 269.0 \mathrm{pg} / \mathrm{mL}$ in eutopic endometrium $(n=17)$ and $622.9 \pm 193.0 \mathrm{pg} / \mathrm{mL}$ in normal endometrium $(n=18)$. Ectopic lesions and eutopic endometrium had significantly higher E2 concentrations compared with normal endometrium $(P<0.001)$. Moreover, the difference in E2 concentrations between ectopic and eutopic endometrium had statistical significance $(P<0.001)$. During the proliferative phase, eutopic and normal endometrium $E_{2}$ concentrations were higher $(n=11, \quad 2060.7 \pm 214.9 \mathrm{pg} / \mathrm{mL} ; \quad n=13$, $759.4 \pm 175.6 \mathrm{pg} / \mathrm{mL}$ ) than those in the secretory
$\mathrm{Nm}$

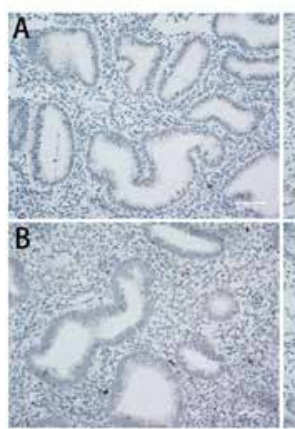

A

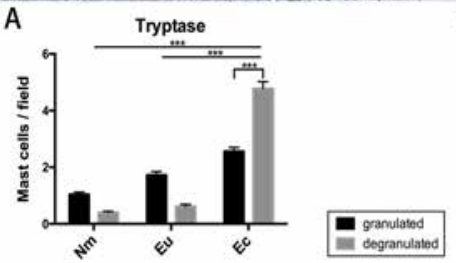

$\mathrm{Eu}$

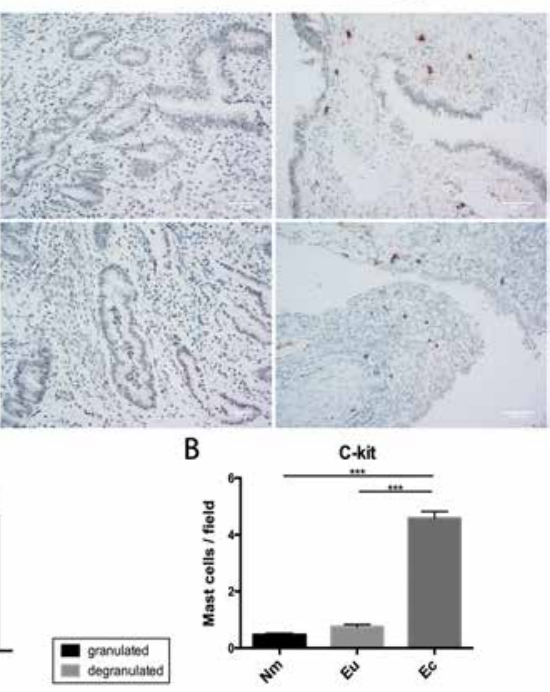

Figure 2 Immunohistochemistry and statistical analysis of MCs in different endometrial tissues following staining with tryptase (A) and $\mathrm{C}-\mathrm{kit}(\mathrm{B})$. The graph represents the number of MCs counted in five fields ( $\times 20$ objective, $\times 10$ ocular) for each patient, with error bars representing S.E.M. Ec, ectopic endometrium; Eu, eutopic endometrium; Nm, normal endometrium. Scale bars $=500 \mu \mathrm{m}$. $* * * P<0.001$. phase $(n=6,1680.3 \pm 195.0 \mathrm{pg} / \mathrm{mL}, P=0.003 ; n=5$, $486.4 \pm 148.7 \mathrm{pg} / \mathrm{mL}, P=0.007)$, but there was no significant difference in E2 concentrations between the proliferative $(n=9,1624.5 \pm 274.5 \mathrm{pg} / \mathrm{mL})$ and secretory phase $(n=8,1496.9 \pm 180.5 \mathrm{pg} / \mathrm{mL})$ in ectopic lesions $(P=0.282)$. In addition, during the proliferative and secretory phase, E2 levels in ectopic lesions or eutopic endometrium were significantly higher than those of normal endometrium $(P<0.001$; Table 3$)$.

CYP19 expression was significantly higher in ectopic lesions when compared with either eutopic endometrium or control endometrium $(P<0.001)$, whereas 17BHSD2 expression was significantly higher in normal endometrium compared with eutopic endometrium $(P<0.001)$ or ectopic lesions $(P<0.001)$. Moreover, sulfate transferase expression was statistically higher in normal endometrium than in eutopic endometrium $(P=0.002)$, although the difference between normal and ectopic endometrium did not reach statistical significance $(P=0.053$; Supplementary Fig. 1, see section on supplementary data given at the end of this article).

Next, we investigated whether the concentrations of E2 in serum or ectopic lesions were associated with the severity of dysmenorrhea; Pearson correlation confirmed that E2 concentrations in ectopic lesions were moderately $(r=0.575, P=0.016)$ correlated with the degree of dysmenorrhea, whereas the concentrations of E2 in serum were not $(r=0.339, P=0.183$; Fig. 1$)$.
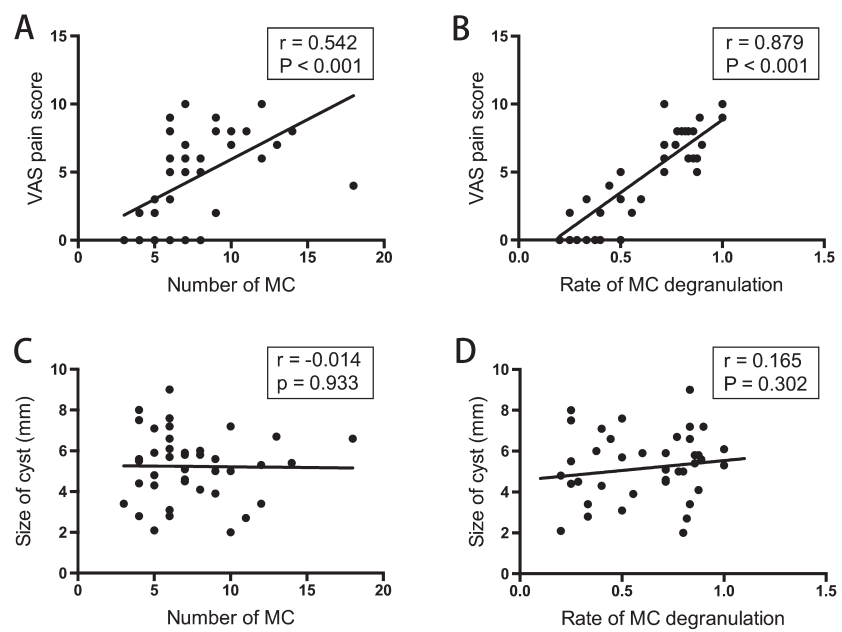

Figure $3 \mathrm{~A}$ high number of MCs and the rate of degranulation in ovarian endometriotic lesions were positively correlated with endometriosis-related dysmenorrhea but not the size of ovarian endometriotic cysts. (A) Correlation between the number of MCs and the degree of dysmenorrhea. (B) Correlation between the rate of $\mathrm{MC}$ degranulation and the degree of dysmenorrhea. (C) Correlation between the number of MCs and the size of ovarian endometriotic cysts. (D) Correlation between the rate of MC degranulation and the size of ovarian endometriotic cysts. Each dot represents data from an individual patient. The Pearson coefficient of correlation and the significance of this correlation are shown in the lower right corner. 

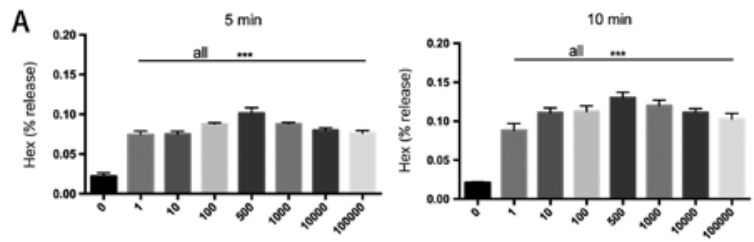

Concentration of $\mathrm{E} 2$ ( $\mathrm{pmol}$ )

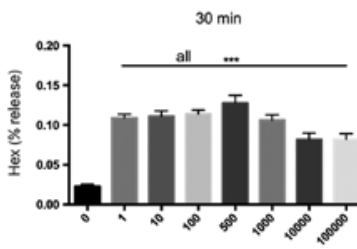

Concentration of E2 (pmoll)

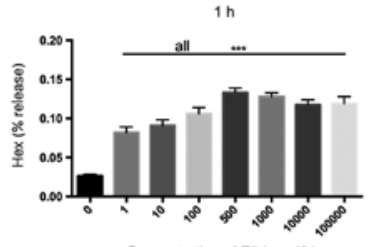

Concentration of $\mathrm{E} 2$ (pmol)

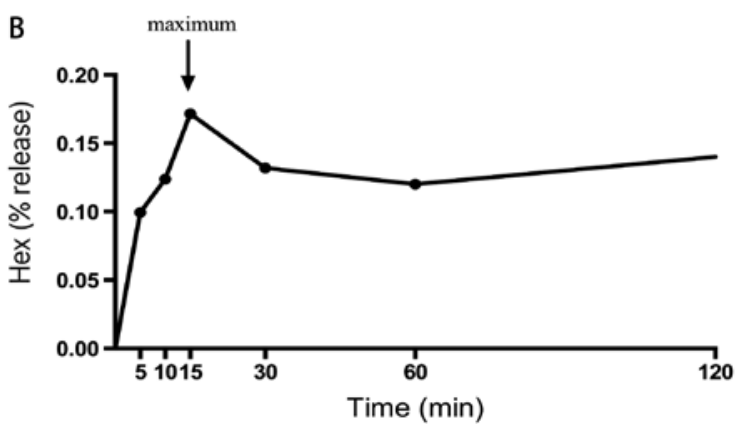

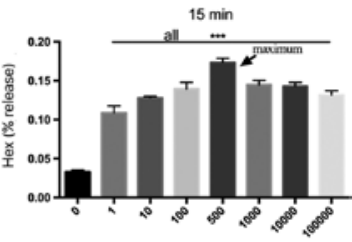

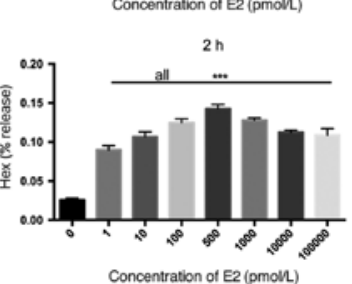

Figure 4 Increased rate of RBL2H3 cell degranulation in high E2 concentrations. (A) Rates of degranulation after RBL2H3 cells were stimulated with various concentrations of E2 at 5, 10, 15, 30, 60 and 120 min; the most suitable E2 concentration of RBL2H3 cells degranulation was $500 \mathrm{pmol} / \mathrm{L}$ (indicated by the arrow). (B) Rates of degranulation after RBL2H3 cells were stimulated with $500 \mathrm{pmol} / \mathrm{L}$ E2 over $120 \mathrm{~min}$; peak degranulation rate occurred at $15 \mathrm{~min}$ (indicated by the arrow). For all experiments, $n=3$. $* * * P<0.001$.

\section{A high number of MCs and the rate of degranulation in ovarian endometriotic lesions are positively correlated with endometriosis-related dysmenorrhea but not the size of ovarian endometriotic cysts}

Tryptase-positive MCs were noted around blood vessels and the interstitium with fibrosis. The ratio of granulated/degranulated/total MCs $(\times 20$ objective, $\times 10$ ocular, mean \pm S.E.M.) in ectopic lesions $(2.6 \pm 0.1 / 4.8 \pm 0.3 / 7.4 \pm 0.2)$ was greater than that in eutopic endometria $(1.7 \pm 0.1 / 0.6 \pm 0.1 / 2.3 \pm 0.2$, $P<0.001)$ and normal endometria $(1.0 \pm 0.1 / 0.4 \pm 0.04 / 1.4 \pm 0.1, P<0.001)$. Furthermore, the number of degranulated MCs was also significantly higher than granulated MCs in ectopic lesions $(P<0.001$; Fig. 2A).

C-kit (CD117) was expressed by almost all degranulated MCs and showed a similar distribution of tryptase. The number of degranulated MCs in ovarian

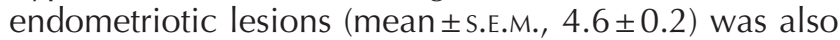
significantly higher when compared with endometriotic endometrium (mean \pm S.E.M., $0.8 \pm 0.1, P<0.001$ ) and control endometrium (mean \pm S.E.M., $0.5 \pm 0.1, P<0.001$; Fig. 2B). Combined with clinical information, the number of MCs and the rate of degranulation were not significantly related with the menstrual cycle $(P>0.05)$.

Next, we investigated whether degranulated MCs were associated with clinical parameters; Pearson correlation showed that the total number of MCs, and the rates of degranulated/total MCs, were correlated with the severity of dysmenorrhea $(r=0.542, P<0.001$; $r=0.879, P<0.001)$, but not with the size of ovarian endometriotic cysts $(r=-0.014, P=0.933 ; r=0.165$, $P=0.302$; Fig. 3).

\section{Increased rate of $\mathrm{RBL} 2 \mathrm{H} 3$ cell degranulation in high E2 concentrations}

High concentrations of E2 a high number of MCs and high rates of degranulation are all significantly higher in ovarian endometriotic cysts than in controls. To determine whether E2 concentration was correlated with MC degranulation rate, $\mathrm{RBL} 2 \mathrm{H} 3$ cells were cultured in vitro and treated with different concentrations of E2. Various concentrations of E2 were shown to stimulate RBL2H3 cell degranulation $(P<0.001)$. The maximum $\mathrm{MC}$ degranulation rate of $\mathrm{RBL} 2 \mathrm{H} 3$ cells occurred at $500 \mathrm{pmol} / \mathrm{L}$ of E2 (Fig. 4A), and although different E2 concentrations could trigger MC degranulation within a 5-min time period, maximal rates of degranulation occurred at $15 \mathrm{~min}$ (Fig. 4B).

\section{Activation of $\mathrm{RBL} 2 \mathrm{H} 3$ cells by E2 can trigger the release of biologically active NGF}

As MC degranulation was correlated with endometriosisrelated dysmenorrhea, PC12 cells were then cultured in vitro and treated with the supernatant of RBL2H3 cells that had been previously treated with $500 \mathrm{pmol} / \mathrm{L}$ E2. As shown in Fig. 5A, 21.4\% of PC12 cells cultured with medium alone expressed at least two neurites with sizes of $\geq 50 \mu \mathrm{m}$. At a concentration of $2 \mathrm{ng} / \mathrm{mL}, \mathrm{NGF}$ produced striking neurite outgrowth in PC12 cells, 

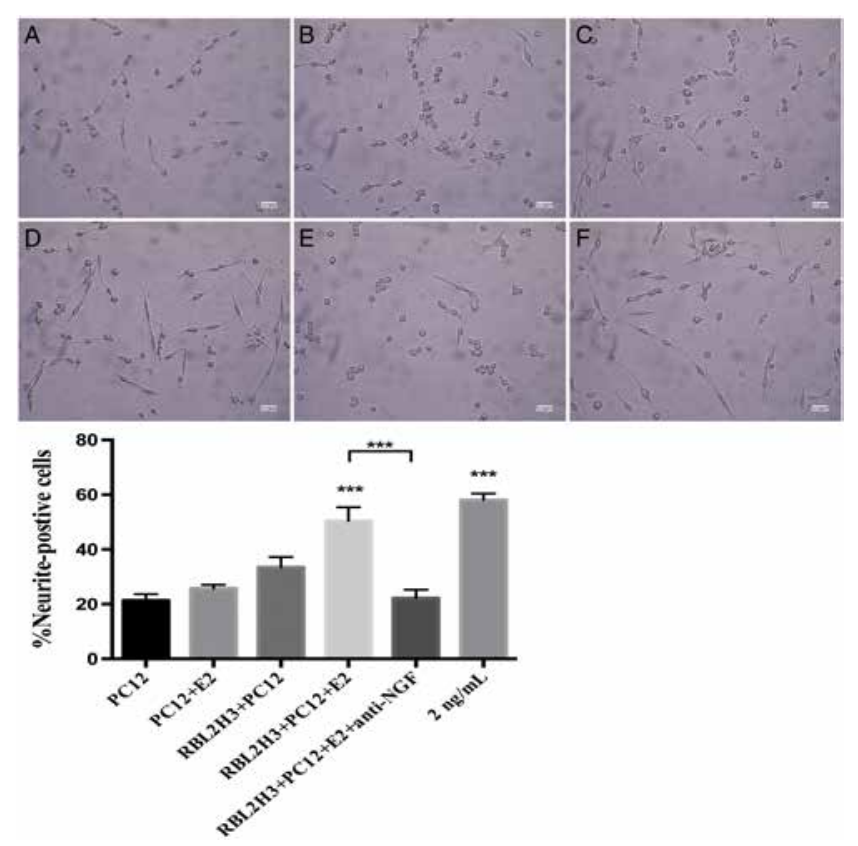

Figure 5 Activation of RBL2H3 cells by E2 can trigger the release of biologically active NGF. (A) PC12 cell complete culture medium. (B) PC12 cells cultured for $24 \mathrm{~h}$ with $500 \mathrm{pmol} / \mathrm{L}$ E2. (C) Supernatants from RBL2H3 cells $\left(1 \times 10^{6}\right.$ cell $\left./ \mathrm{mL}\right)$ cultured for $24 \mathrm{~h}$ without E2 stimulation. (D) Supernatants from RBL2H3 cells $\left(1 \times 10^{6}\right.$ cells/mL) cultured for $24 \mathrm{~h}$ with $500 \mathrm{pmol} / \mathrm{L}$ E2. (E) Replicate activated RBL2H3 cell supernatants with $100 \mathrm{ng} / \mathrm{mL}$ of anti-NGF antibody. (F) $2 \mathrm{ng} / \mathrm{mL}$ NGF. After $24 \mathrm{~h}$, the number of PC12 cells with at least two neurites that were approximately $50 \mu \mathrm{m}$ or longer was determined on a dark field inverted microscope. Data are shown as mean \pm S.E.M. For all experiments, $n=5$. Scale bars $=200 \mu \mathrm{m} .{ }^{* * *} P<0.001$.

resulting in $58 \%$ of cells expressing neurites (Fig. 5F). When the supernatants of RBL2H3 cells incubated with $500 \mathrm{pmol} / \mathrm{L}$ E2 for $24 \mathrm{~h}$ were added to PC12 cells instead of medium, the number of neurite-positive cells increased significantly $(50.4 \% \pm 5.0 \%, P<0.001$; Fig. 5D). By contrast, supernatants from $\mathrm{RBL} 2 \mathrm{H} 3$ cells incubated with medium alone (Fig. 5C) or with an NGF receptor
A

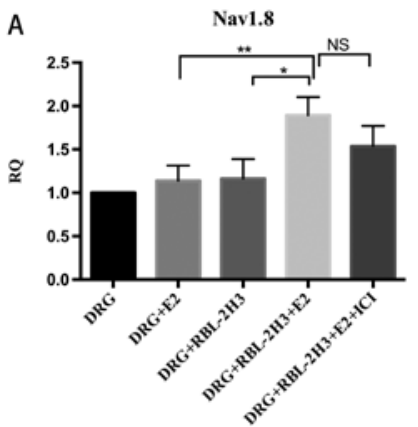

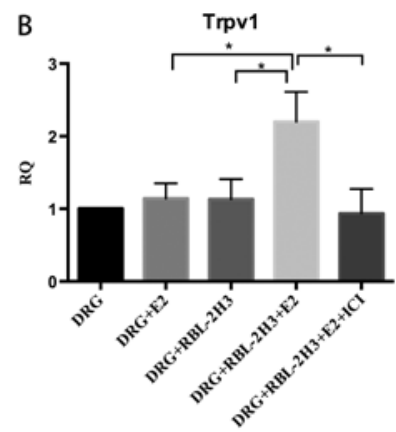

Figure 6 Activation of RBL2H3 cells by E2 can promote the peripheral sensitization of DRG cells. (A) Nav1.8 (B) Trpv1. RQ, relative quantification. Data show mean \pm S.E.M. For all experiments, $n=3 .{ }^{*} P<0.05,{ }^{* *} P<0.01$. blocker (Fig. 5E) did not promote neurite outgrowth. Thus, supernatants from RBL2H3 cells incubated with E2 are likely to contain biologically active NGF that can stimulate neurite elongation in PC12 cells.

\section{Activation of RBL2H3 cells by 22 can promote the peripheral sensitization of DRG cells}

We used a co-culture of RBL2H3 cells and DRG cells in vitro, which was stimulated with E2 (500 pmol/L) or ICI182780, to investigate whether E2 mediates the role of MCs in the peripheral sensitization of DRG cells. As shown in Fig. 6, the expression levels of Nav1.8 in DRG cells were upregulated after E2 treatment during co-culture with RBL2H3 $(P=0.015)$. This upregulated level of expression was partially blocked by ICI182780, although this effect was not statistically significant $(P=0.121)$. Furthermore, the expression of transient receptor potential cation channel subfamily $\mathrm{V}$ member 1 (Trpv1) in DRG cells was also upregulated after treatment with E2 $(P=0.020)$ and was blocked completely by ICI182780 $(P=0.015)$.
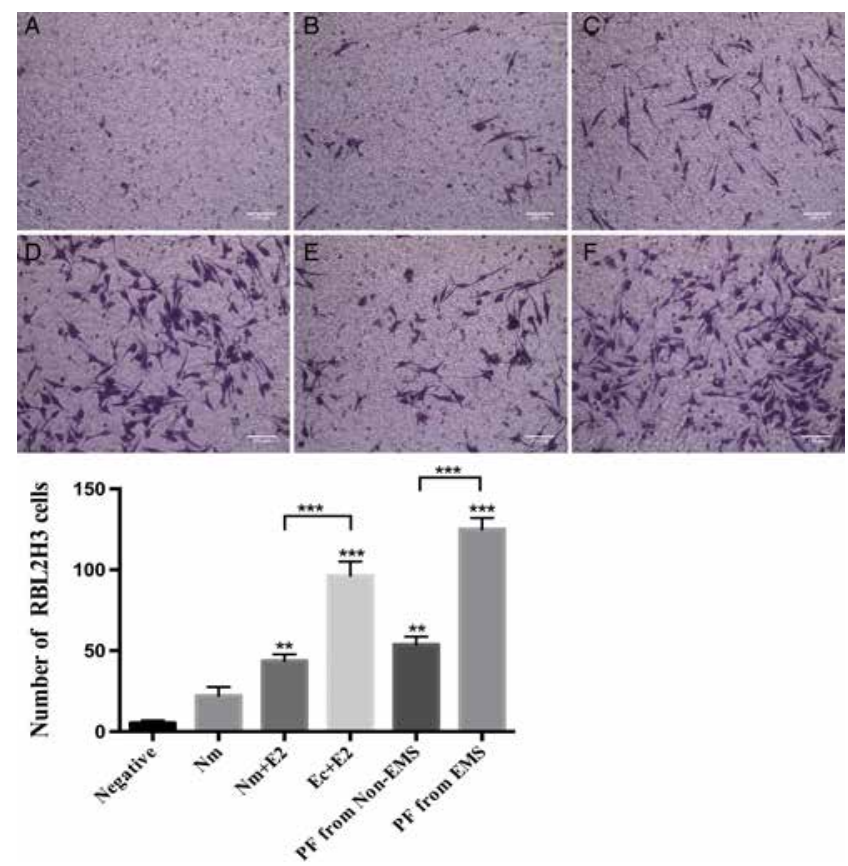

Figure 7 Endometriotic cells with E2 treatment, and peritoneal fluid collected from patients with endometriosis, can promote RBL2H3 cell recruitment. (A) (Negative control) Endometrial cell complete culture medium. (B) (Standard control) Supernatants from normal endometrial cells cultured for $24 \mathrm{~h}$ without E2 stimulation. (C) Supernatants from normal endometrial cells cultured for $24 \mathrm{~h}$ with $10^{-7} \mathrm{~mol} / \mathrm{L}$ E2 (D) Supernatants from ectopic endometrial cells cultured for $24 \mathrm{~h}$ with $10^{-7} \mathrm{~mol} / \mathrm{L} \mathrm{E} 2$. (E) Peritoneal fluid from patients without endometriosis. (F) Peritoneal fluid from patients with endometriosis. For all experiments, $n=3$. Scale bars $=200 \mu \mathrm{m}$. ${ }^{* *} P<0.01, * * * P<0.001$. 

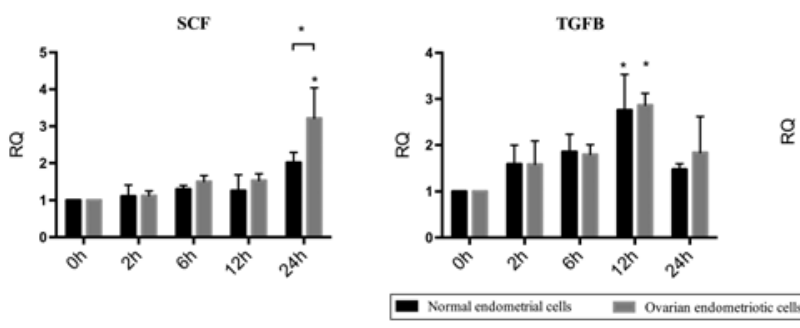

\section{Endometriotic cells can promote $\mathrm{RBL} 2 \mathrm{H} 3$ cell recruitment by upregulating the expression levels of related cytokines}

Although E2 concentrations in endometriotic lesions were correlated with the rate of MC degranulation, the relevance of high local concentrations of E2, the total number of MCs and the effect of E2 on MC recruitment in endometriotic lesions remains unclear. Therefore, we created a micro-environment of high local concentration of $\mathrm{E} 2$, which was similar to that seen in endometriotic lesions. The supernatant from ovarian endometriotic cells (Fig. 7D) in the lower chamber space that was previously stimulated with $10^{-7} \mathrm{~mol} / \mathrm{L}$ E2 for $24 \mathrm{~h}$ recruited more MCs compared with the control $(P<0.001$; Fig. 7C). Moreover, peritoneal fluid from patients with endometriosis (Fig. 7F) also recruited more MCs than from patients without endometriosis $(P<0.001$; Fig. 7E).

MCs were recruited under the influence of E2 in endometriotic lesions, and to investigate the release of key active mediators released from endometrial cells, we determined the mRNA levels of SCF, transforming growth factor- $\beta$ (TGFB) and monocyte chemoattractant protein-1 (MCP1) using RT-PCR in endometrial cells, which were induced by E2. The levels of SCF mRNA expression in both control endometrial cells and ovarian endometriotic cells increased gradually with increased intervention time, reaching maximal levels $24 \mathrm{~h}$ after intervention with E2. However, the expression level of SCF in ectopic endometrial cells was significantly higher than that of control endometrial cells $(P=0.042)$. Similar to SCF, the expression levels of TGFB and MCP1 mRNA also increased with increasing intervention time but reached a maximum at $12 \mathrm{~h}$ and then decreased. Nevertheless, following E2 treatment, the mRNA expression levels of SCF, TGFB and MCP1 in ectopic endometrial cells were higher than that of control endometrial cells (Fig. 8).

\section{Discussion}

Our previous research proved that the activity of MCs in endometriotic lesions was associated with serum E2 levels and also the expression levels of TNFA in the serum, and NGF in endometriotic lesions (Lin et al. 2015). In this present study, we found that high levels of E2 in ovarian endometriomas could recruit and activate MCs, which were then able to release NGF and promote nerve growth and the sensitization of nerve fibers, which may play a role in endometriosisassociated dysmenorrhea.

Our results showed that CYP19 expression in endometriotic lesions was increased, whereas the expression levels of 17BHSD2 and sulfate transferase in ovarian endometriotic lesions were reduced when compared with control endometrium. The aberrant expression of estrogen-metabolizing enzymes led to elevated E2 concentrations in local ovarian endometriomas. Combined with clinical parameters, we further confirmed that local high levels of E2 in endometriosis lesions were positively related to pain symptoms in patients with endometriosis; in contrast, the concentrations of E2 in serum were not. Several studies have demonstrated that high levels of E2 can not only promote ectopic endometrial cells to secrete a series of cytokines to participate in pain symptoms (Rizner 2009, Ferrero et al. 2014), but can also act on immune cells accumulating in the lesions to accelerate the disease process (Garzetti et al. 1993, Greaves et al. 2015). Interestingly, our study demonstrated that the number and activity of MCs were higher in ovarian endometriotic lesions compared with controls, as reported by other studies (Matsuzaki et al. 1998, Sugamata et al. 2005). Moreover, a high number of MCs

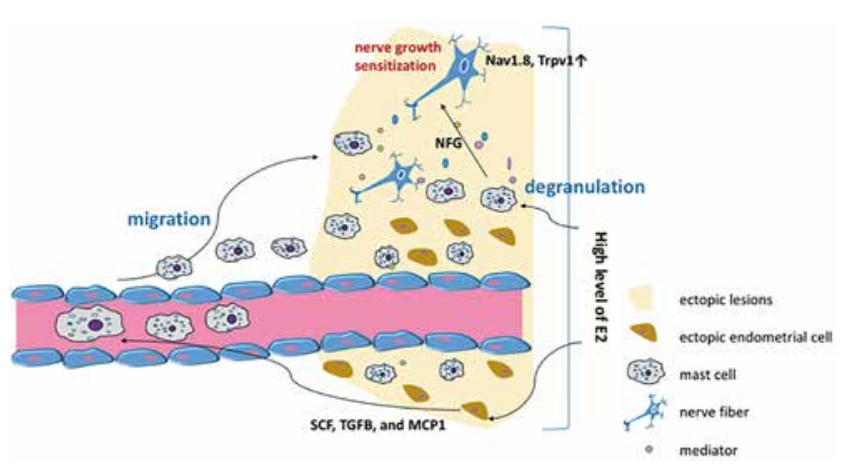

Figure 9 Schematic diagram of key findings. This study showed that high levels of E2 in ovarian ectopic lesions can promote MC recruitment by up-regulating the expression levels of SCF, TGFB, and MCP1 in ectopic endometrial cells. Additionally, high levels of E2 could directly trigger $\mathrm{MC}$ degranulation leading to the release of biologically- active NGF, which can promote nerve growth and the sensitization of nerve fibers by up-regulating the expression of Nav1.8 and Trpv1. 
and the rate of degranulation in ovarian endometriotic lesions were also positively correlated with the extent of the associated dysmenorrhea but not with the size of ovarian cysts. As MCs have been reported to express E2 receptors (Zaitsu et al. 2007), it is suggested that local high levels of E2 may have an effect on the activation of MCs that are involved in endometriotic pain.

In our RBL2H3 cell culture experiments, we found that the degranulation of MCs increased swiftly after the cells were treated with E2; moreover, this effect did not require IgE cross-linking, suggesting that E2 treatment stimulates MCs to release mediators in a direct manner. Furthermore, the optimum concentration of E2 was equivalent to the local concentration of E2 in ovarian endometritic lesions, which may partly explain the high rate of degranulation in local endometriotic lesions.

Our results further provide evidence that E2 can trigger $\mathrm{RBL} 2 \mathrm{H} 3$ cells to release biologically active NGF that can stimulate neurite elongation in PC12 cells, which is consistent with previous studies, which reported that MCs can synthesize, store and release NGF (Leon et al. 1994). On the one hand, NGF acts as a chemoattractant, thereby causing an increase in the number of MCs, as well as their degranulation (Horigome et al. 1993, Marshall et al. 1999, Rizner 2009), and on the other hand, NGF can promote nerve growth and induce the expression of neuropeptides and lower the threshold of neurons for firing (Lindsay \& Harmar 1989). As previously reported, MCs are located close to nerve fibers, which makes them an ideal candidate for modulating neural activity and nociception (Anaf et al. 2006, Aich et al. 2015). Additionally, using co-cultures of RBL2H3 cells and DRG cells in vitro, our results showed that the stimulation of MCs by E2 can upregulate the expression of Nav1.8 and Trpv 1 in DRG cells. Both of these mechanisms contribute to peripheral sensitization, a particular form of stimulusevoked functional plasticity of the nociceptor, to reduce its firing threshold and increase responsiveness (Zhuang et al. 2004). Nav1.8 contributes the most to sustaining the depolarizing stage of action potentials in nociceptive sensory neurons (Renganathan et al. 2001, Blair \& Bean 2002), while Trpv 1 predominantly transmits heat and pain sensation and plays a role in interactions between the inflammatory environment, pain and hyperalgesia (Koerber et al. 2010). The former has been extensively reported to play a role in neuropathic pain (Lai et al. 2003), while the latter has been reported to participate in the process of pain in patients with endometriosis (Liu et al. 2012) or rat models of endometriosis (Lian et al. 2017). The upregulated expression of Nav1.8 and Trpv1 under a co-culture environment of RBL2H3 cells under the stimulation of E2 indicated that E2 can stimulate MC degranulation to participate in the process of pain, which may provide a partial explanation for the fact that local high levels of E2, and the activity of MCs, have a positive correlation with endometriosis-related dysmenorrhea. Furthermore, our data showed that Nav1.8 and Trpv1 were important targeting molecules of MC-DRG cell interaction, which can also provide new treatments for relieving endometriosis pain in addition to stabilizing MC in endometriotic lesions (Joshi et al. 2009).

As previously documented, E2 can regulate the expression of the chemokine receptors CCR4 and CCR5 in the HMC-1 cell line, as well as CCR3 and CCR5 in BMMCs (Jensen et al. 2010), thus indicating an involvement in the recruitment of MCs. Here, we tentatively propose that a micro-environment with high levels of E2 can promote the recruitment of MCs by upregulating factors such as SCF, TGFB and MCP1 in ectopic endometrial cells, which may partly explain the higher number of MCs in endometriotic lesions than controls. Moreover, peritoneal fluid from patients with endometriosis can also recruit more MCs than patients without endometriosis, which is in accordance with the discovery of increased levels of SCF, a multi-functional growth factor, which plays an important role in the recruitment of MCs, in the peritoneal fluid of women with endometriosis compared to those without (Osuga et al. 2000).

In summary, our experiment proved that high local concentrations of E2 are associated with the number of MCs, and the rate of degranulation in local ovarian endometriotic lesions and play a role in the pathogenesis of endometriosis-associated dysmenorrhea. Ectopic endometrial cells stimulated with E2 can promote $\mathrm{RBL} 2 \mathrm{H} 3$ cell recruitment by upregulating the expression levels of SCF, TGFB and MCP1. Furthermore, high local levels of E2 can directly stimulate the degranulation of MCs, which can trigger the release of biologically active NGF and promote the peripheral sensitization of DRG cells, a process that may also play a role in endometriosis-related dysmenorrhea. (Fig. 9).

While we believe that high local concentrations of E2 can induce the activation of MCs, which play a role in endometriosis pain, our study features some limitations, which should be taken into account when interpreting our findings. First, we used an MC line as a target cell; these do not behave in the exact same manner as MCs in patients with endometriosis. As there are no known methods that can be used to separate primary MCs from specific phenotypes in patients with endometriosis, future studies should be carried out using primary MCs from the peritoneal fluid of a rat model of endometriosis. Secondly, because our experimental ideas are based on previous animal experiments published in 2015 (Lin et al. 2015), this study draws conclusions mainly through the analysis of tissue samples from patients and experiments using different rat cell lines in vitro but without animal experiments. As this is a continuous study, we will further validate and deepen our research in the next animal experiments.

Endometriosis is widely viewed as an estrogendependent disease (Eskenazi \& Warner 1997, Rizner 2009, Ferrero et al. 2014). Our present data highlight 
the importance of high local concentrations of E2 in mediating the degranulation and recruitment of MCs in ovarian endometriotic lesions, which are hypothesized to play an important role in endometriosis-related dysmenorrhea. Based on this point of view, we provide clinically relevant evidence that the reduction of E2 in local endometriotic lesions could alleviate pain in patients, and further suggest that membrane stabilizers that inhibit MC degranulation may hold promise for endometriosis treatment in the future.

\section{Supplementary data}

This is linked to the online version of the paper at https://doi.org/10.1530/REP-17-0457.

\section{Declaration of interest}

The authors declare that there is no conflict of interest that could be perceived as prejudicing the impartiality of the research reported.

\section{Funding}

This work was supported by the National Key Research and Development Program of China (grant number 2017YFC1001202) and the National Natural Science Foundation of China (grant numbers 81471433, 81671429).

\section{Acknowledgements}

The authors thank all of the participants and healthcare professionals who were involved in this study. They particularly acknowledge Yun-Zheng Chen and Ping-Xu for their assistance with sample collection. They also thank Yan-Jun Ma and Qi-Chen for their excellent technical support.

\section{References}

Aich A, Afrin LB \& Gupta K 2015 Mast cell-mediated mechanisms of nociception. International Journal of Molecular Sciences $\mathbf{1 6}$ 29069-29092. (https://doi.org/10.3390/ijms161226151)

Anaf V, Chapron C, El Nakadi I, De Moor V, Simonart T \& Noel JC 2006 Pain, mast cells, and nerves in peritoneal, ovarian, and deep infiltrating endometriosis. Fertility and Sterility 86 1336-1343. (https://doi. org/10.1016/j.fertnstert.2006.03.057)

Barsumian EL, Isersky C, Petrino MG \& Siraganian RP 1981 IgE-induced histamine release from rat basophilic leukemia cell lines: isolation of releasing and nonreleasing clones. European Journal of Immunology $\mathbf{1 1}$ 317-323. (https://doi.org/10.1002/eji.1830110410)

Blair NT \& Bean BP 2002 Roles of tetrodotoxin (TTX)-sensitive Na+ current, TTX-resistant Na+ current, and Ca2+ current in the action potentials of nociceptive sensory neurons. Journal of Neuroscience 22 10277-10290.

Burney RO \& Giudice LC 2012 Pathogenesis and pathophysiology of endometriosis. Fertility and Sterility 98 511-519. (https://doi. org/10.1016/j.fertnstert.2012.06.029)

Canis M, Donnez JG, Guzick DS, Halme JK, Rock JA, Schenken RS \& Vemon MW 1997 Revised American Society for reproductive medicine classification of endometriosis: 1996. Fertility and Sterility 67 817-821. (https://doi.org/10.1016/S0015-0282(97)81391-X)
Chapron C, Souza C, Borghese B, Lafay-Pillet MC, Santulli P, Bijaoui G, Goffinet F \& de Ziegler D 2011 Oral contraceptives and endometriosis: the past use of oral contraceptives for treating severe primary dysmenorrhea is associated with endometriosis, especially deep infiltrating endometriosis. Human Reproduction 26 2028-2035. (https:// doi.org/10.1093/humrep/der156)

Church MK \& Levi-Schaffer F 1997 The human mast cell. Journal of Allergy and Clinical Immunology 99 155-160. (https://doi.org/10.1016/S00916749(97)70089-7)

Dastych J, Walczak-Drzewiecka A, Wyczolkowska J \& Metcalfe DD 1999 Murine mast cells exposed to mercuric chloride release granuleassociated N-acetyl-beta-D-hexosaminidase and secrete IL-4 and TNFalpha. Journal of Allergy and Clinical Immunology 103 1108-1114. (https://doi.org/10.1016/S0091-6749(99)70186-7)

Eskenazi B \& Warner ML 1997 Epidemiology of endometriosis. Obstetrics and Gynecology Clinics of North America 24 235-258. (https://doi. org/10.1016/S0889-8545(05)70302-8)

Ferrero S, Remorgida V, Maganza C, Venturini PL, Salvatore S, Papaleo E, Candiani M \& Leone Roberti Maggiore U 2014 Aromatase and endometriosis: estrogens play a role. Annals of the New York Academy of Sciences 1317 17-23. (https://doi.org/10.1111/nyas.12411)

Garzetti GG, Ciavattini A, Provinciali M, Fabris N, Cignitti M \& Romanini C 1993 Natural killer cell activity in endometriosis: correlation between serum estradiol levels and cytotoxicity. Obstetrics and Gynecology $\mathbf{8 1}$ 665-668.

Greaves E, Temp J, Esnal-Zufiurre A, Mechsner S, Horne AW \& Saunders PT 2015 Estradiol is a critical mediator of macrophage-nerve cross talk in peritoneal endometriosis. American Journal of Pathology $\mathbf{1 8 5}$ 2286-2297. (https://doi.org/10.1016/j.ajpath.2015.04.012)

Greene LA \& Tischler AS 1976 Establishment of a noradrenergic clonal line of rat adrenal pheochromocytoma cells which respond to nerve growth factor. PNAS 73 2424-2428. (https://doi.org/10.1073/ pnas.73.7.2424)

Horigome K, Pryor JC, Bullock ED \& Johnson EM Jr 1993 Mediator release from mast cells by nerve growth factor. Neurotrophin specificity and receptor mediation. Journal of Biological Chemistry 268 14881-14887.

Huhtinen K, Desai R, Stahle M, Salminen A, Handelsman DJ, Perheentupa A \& Poutanen M 2012 Endometrial and endometriotic concentrations of estrone and estradiol are determined by local metabolism rather than circulating levels. Journal of Clinical Endocrinology and Metabolism 97 4228-4235. (doi.org/10.1210/jc.2012-1154)

luvone T, Affaitati G, De Filippis D, Lopopolo M, Grassia G, Lapenna D, Negro L, Costantini R, Vaia M, Cipollone F et al. 2016 Ultramicronized palmitoylethanolamide reduces viscerovisceral hyperalgesia in a rat model of endometriosis plus ureteral calculosis: role of mast cells. Pain 157 80-91. (https://doi.org/10.1097/j. pain.0000000000000220)

Jensen F, Woudwyk M, Teles A, Woidacki K, Taran F, Costa S, Malfertheiner SF \& Zenclussen AC 2010 Estradiol and progesterone regulate the migration of mast cells from the periphery to the uterus and induce their maturation and degranulation. PLOS ONE 5 e14409. (https:// doi.org/10.1371/journal.pone.0014409)

Joshi SK, Honore P, Hernandez G, Schmidt R, Gomtsyan A, Scanio M, Kort M \& Jarvis MF 2009 Additive antinociceptive effects of the selective Nav1.8 blocker A-803467 and selective TRPV1 antagonists in rat inflammatory and neuropathic pain models. Journal of Pain 10 306-315. (https://doi.org/10.1016/j.jpain.2008.09.007)

Kelm Junior AR, Lancellotti CL, Donadio N, Auge AP, Lima SM, Aoki T \& Ribeiro PA 2008 Nerve fibers in uterosacral ligaments of women with deep infiltrating endometriosis. Journal of Reproductive Immunology $\mathbf{7 9}$ 93-99. (https://doi.org/10.1016/j.jri.2008.08.004)

Kleij HP \& Bienenstock J 2005 Significance of conversation between mast cells and nerves. Allergy, Asthma and Clinical Immunology 1 65-80. (https://doi.org/10.1186/1710-1492-1-2-65)

Koerber HR, Mcllwrath SL, Lawson JJ, Malin SA, Anderson CE, Jankowski MP \& Davis BM 2010 Cutaneous C-polymodal fibers lacking TRPV1 are sensitized to heat following inflammation, but fail to drive heat hyperalgesia in the absence of TPV1 containing C-heat fibers. Molecular Pain 6 58. (doi.org/10.1186/1744-8069-6-58)

Kuehn HS, Radinger M \& Gilfillan AM 2010 Measuring mast cell mediator release. Current Protocols in Immunology 7 38. (https://doi. org/10.1002/0471142735.im0738s91) 
Lai J, Hunter JC \& Porreca F 2003 The role of voltage-gated sodium channels in neuropathic pain. Current Opinion in Neurobiology 13 291-297. (https://doi.org/10.1016/S0959-4388(03)00074-6)

Leon A, Buriani A, Dal Toso R, Fabris M, Romanello S, Aloe L \& LeviMontalcini R 1994 Mast cells synthesize, store, and release nerve growth factor. PNAS 91 3739-3743. (https://doi.org/10.1073/pnas.91.9.3739)

Lian YL, Cheng MJ, Zhang XX \& Wang L 2017 Elevated expression of transient receptor potential vanilloid type 1 in dorsal root ganglia of rats with endometriosis. Molecular Medicine Reports 16 1920-1926. (https://doi.org/10.3892/mmr.2017.6783)

Lin KQ, Zhu LB, Zhang XM \& Lin J 2015 Role of mast cells in estrogenmediated experimental endometriosis in rats. Zhejiang da xue xue bao Yi xue ban $44269-277$.

Lindsay RM \& Harmar AJ 1989 Nerve growth factor regulates expression of neuropeptide genes in adult sensory neurons. Nature 337 362-364. (https://doi.org/10.1038/337362a0)

Liu J, Liu X, Duan K, Zhang Y \& Guo SW 2012 The expression and functionality of transient receptor potential vanilloid 1 in ovarian endometriomas. Reproductive Sciences 19 1110-1124. (https://doi. org/10.1177/1933719112443876)

Marshall JS, Gomi K, Blennerhassett MG \& Bienenstock J 1999 Nerve growth factor modifies the expression of inflammatory cytokines by mast cells via a prostanoid-dependent mechanism. Journal of Immunology $1624271-4276$.

Matsuzaki S, Canis M, Darcha C, Fukaya T, Yajima A \& Bruhat MA 1998 Increased mast cell density in peritoneal endometriosis compared with eutopic endometrium with endometriosis. American Journal of Reproductive Immunology 40 291-294. (https://doi. org/10.1111/j.1600-0897.1998.tb00420.x)

Osuga Y, Koga K, Tsutsumi O, Igarashi T, Okagaki R, Takai Y, Matsumi H, Hiroi H, Fujiwara T, Momoeda M et al. 2000 Stem cell factor (SCF) concentrations in peritoneal fluid of women with or without endometriosis. American Journal of Reproductive Immunology 44 231-235. (https://doi.org/10.1111/j.8755-8920.2000.440407.x)

Priya K, Rajaram S \& Goel N 2016 Comparison of combined hormonal vaginal ring and low dose combined oral hormonal pill for the treatment of idiopathic chronic pelvic pain: a randomised trial. European Journal of Obstetrics and Gynecology and Reproductive Biology 207 141-146. (https://doi.org/10.1016/j.ejogrb.2016.10.026)

Renganathan M, Cummins TR \& Waxman SG 2001 Contribution of $\mathrm{Na}(\mathrm{v}) 1.8$ sodium channels to action potential electrogenesis in DRG neurons. Journal of Neurophysiology 86 629-640.

Rizner TL 2009 Estrogen metabolism and action in endometriosis. Molecular and Cellular Endocrinology 307 8-18. (https://doi. org/10.1016/j.mce.2009.03.022)

Sinaii N, Cleary SD, Ballweg ML, Nieman LK \& Stratton P 2002 High rates of autoimmune and endocrine disorders, fibromyalgia, chronic fatigue syndrome and atopic diseases among women with endometriosis: a survey analysis. Human Reproduction 17 2715-2724. (https://doi. org/10.1093/humrep/17.10.2715)

Sugamata M, Ihara T \& Uchiide I 2005 Increase of activated mast cells in human endometriosis. American Journal of Reproductive Immunology 53 120-125. (https://doi.org/10.1111/j.1600-0897.2005.00254.x)

Woo SB, Timm DE \& Neet KE 1995 Alteration of NH2-terminal residues of nerve growth factor affects activity and Trk binding without affecting stability or conformation. Journal of Biological Chemistry 270 6278-6285. (https://doi.org/10.1074/jbc.270.11.6278)

Xiong W, Zhang L, Yu L, Xie W, Man Y, Xiong Y, Liu H \& Liu Y 2015 Estradiol promotes cells invasion by activating beta-catenin signaling pathway in endometriosis. Reproduction 150 507-516. (https://doi. org/10.1530/REP-15-0371)

Zaitsu M, Narita S, Lambert KC, Grady J, Estes DM, Curran EM, Brooks EG, Watson CS, Goldblum RM \& Midoro-Horiuti T 2007 Estradiol activates mast cells via a non-genomic estrogen receptor-alpha and calcium influx. Molecular Immunology 44 1977-1985. (https://doi. org/10.1016/j.molimm.2006.09.030)

Zeitoun KM \& Bulun SE 1999 Aromatase: a key molecule in the pathophysiology of endometriosis and a therapeutic target. Fertility and Sterility 72 961-969. (https://doi.org/10.1016/S0015-0282(99)00393-3)

Zeitoun K, Takayama K, Sasano H, Suzuki T, Moghrabi N, Andersson S, Johns A, Meng L, Putman M, Carr B et al. 1998 Deficient 17betahydroxysteroid dehydrogenase type 2 expression in endometriosis: failure to metabolize 17beta-estradiol. Journal of Clinical Endocrinology and Metabolism 83 4474-4480. (https://doi.org/10.1210/jcem.83.12.5301)

Zenclussen AC, Gerlof K, Zenclussen ML, Sollwedel A, Bertoja AZ, Ritter T, Kotsch K, Leber J \& Volk H-D 2005 Abnormal T-cell reactivity against paternal antigens in spontaneous abortion. American Journal of Pathology 166 811-822. (https://doi.org/10.1016/S0002-9440(10)62302-4)

Zhu LB, Lin KQ, Zhang XM \& Lin J 2015 Sodium cromoglycate attenuates experimental endometriosis in rats by regulating mast cells. Zhejiang $D a$ Xue Xue Bao Yi Xue Ban 44 278-284.

Zhuang ZY, Xu H, Clapham DE \& Ji RR 2004 Phosphatidylinositol 3-kinase activates ERK in primary sensory neurons and mediates inflammatory heat hyperalgesia through TRPV1 sensitization. Journal of Neuroscience 24 8300-8309. (https://doi.org/10.1523/JNEUROSCI.2893-04.2004)

Received 26 July 2017

First decision 21 August 2017

Revised manuscript received 26 September 2017

Accepted 26 October 2017 